\title{
Translation of Chinese Four-character Structures in Documentary Literature: An Interview with a Condemned Prisoner in the Tumbrel
}

\author{
Gao Lei \\ Shaanxi Xueqian Normal University, Shannxi, China, 710100
}

Keywords: Functional Equivalence Theory; Chinese Four-character Structures; Translation Strategy

Abstract: Based on the translation of this novel, this report takes functionalist translation theory as the theoretical basis to study the translation of four-character structures in order to make the rendered version more readable and acceptable for target readers. This report consists of four parts-Task Description, Translation Process, Case Study and Summary. In the Task Description, task background and aims are introduced, as well as the theoretical foundation of the whole report. In the translation process, the report presents three parts of activities, which are pre-translation preparation, translation procedure and post-translation proofreading. In the Case Study, based on the analysis of linguistic features of this text, the report focuses on the features of four-character expressions and proposes four different adaptive translation methods, direct translation, free translation, annotation and omission. The report highlights the characteristics of the novel: the language is usually logic, simple, concise and the informative function is preferred, so reorganization is more often used in the translation of four-character expressions.

\section{Introduction to the Task}

As we all know, there are many English translations of current documentary literature, but the quality of translations varies greatly. When reading English translations, the author finds that many translations are excessively rigid in the language of Chinese texts. Many mistakes appear in terms of language and pragmatics; the translation cannot fully reflect the cultural content of the Chinese text. Due to the lack of readability of the Chinese text's cultural content, it failed to reflect the characteristics of the English novel text.

According to the analysis, this aspect is due to the translator's lack of understanding of Chinese language, poor cultural heritage, and lack of solid foundation in English lead to all these unsatisfactory results. On the other hand, it is because many translators' lack of the relevant literacy theory and do not understand that Chinese and English texts have different language features and textual functions. The translator ignore the attention of readers of the translated language. In today's increasingly frequent foreign exchanges, the author needs a better English translation to reflect the linguistic characteristics of Chinese contemporary documentary literature. 


\section{Theoretical Basis}

\subsection{Brief introduction to Functional Equivalence Theory}

Eugene Nida is the representative of translation theory of Western Linguistics School, who was hailed as "the father of modern translation theory". "Formal equivalence" emphasizes the form and content of the information itself. This kind of equivalence can reflect the linguistic features of the original vocabulary, grammar, and syntactic structure to some extent. In Nida's opinion, "It is important that the extent to which receptors correctly understand and appreciate that translated text accordingly, it is essential in terms of a comparison of the way in which the original receptors understood and appreciate the text and the way in which receptors of the translated text understand and appreciate the translated text......” (Nida,1997:116).

\subsection{Principles for Producing Functional Equivalence}

Through the interpretation of Nida's theory of functional equivalence, we summarize a few principles: 1) The principle of adding proper annotation when the translation adjusts the vocabulary and keeping the literal meaning; 2) The principle of expressing vague semantics clearly; 3) Level and change the structure of the principles of adaptation of the discourse; 4) the same style with the original style but the words are not equal to the principle ; 5) According to the scope of application of the target reader to adapt to the principle of adjustment (Li Shuanzheng, 2004) .

It is not difficult to see from the above principle that translation is not a verbatim translation but a process of re-creation. It is an interpretation of the original, and it should be as faithful as possible to the original. Eugene Nida once said that bilingual and bicultural people really feel that when we read the translated text, we express it when we say this (Nida, 2001) .

\section{Case Study}

\subsection{Literal Translation}

Literal translation is also called word-for-word translation, and it is a traditional method of translation. It refers to the correspondent literal translation. When it comes to literal translation, there are two crucial points. One is to be loyal to the content of source text, and the other is to obey the structure of source text.

Example 1:

This is an effective way for the political and legal departments to promote righteousness and deter criminals.

In this sentence, there are two four-character phrases with the verb-object structure. Such phrases are easy to translate. They are mainly verb-noun structures consisting of verbs. According to the principle of equivalence of information, target language readers are required to obtain the relevant information must be consistent with the meaning of the source language.

Example 2:

Man proposes, Heaven disposes. It's all for heaven's sake. You should be thinking positively!

This sentence in English does not correspond to the words. Here "man proposes" is the reason for autonomy, and "heaven disposes" is the objective reason. Many things must be planned first before they can be realized, but if they are not planned, they will not be successful. It means that they have done their best, as to whether the purpose can be achieved, then depends on the fortune. 


\subsection{Free Translation}

We know that literal translation often can not solve complex translation problems. Sometimes literal translation can not show the meaning of folk sayings, and it will lead to unnecessary misunderstandings, or when there are no equivalent terms to borrow we use literal translation. In this situation, meaning usually takes precedence over form. Therefore, free translation is the most commonly-used method in translating folk vocabulary and idioms.

In addition, free translations are used, especially if the literal and metaphorical meanings of the original text are difficult to keep in the target text. If the image of the original text can not be retained in the translation of folk terminology in China, the translator should convert the image to a more familiar image for the reader. Therefore the functional equivalence can be achieved. Examples are listed below to illustrate this method according to different occasions:

Example 3:

He talks with fervour and assurance in Sichuanese people fast-talking tone mixing with a relatively stiff "Beijing dialect", without hesitation to speak continuously and pleasantly, as if there is a desire to vent, he was lonely for many days before he has seized a chance to get it off his chests.

In this sentence there are two four-character structures . From the surface meaning of the original text, target language readers will have difficulty in understanding their meanings, therefore, the translator should not choose literal translation, so they are translated as: "talks with fervour and assurance" and "speak continuously and pleasantly." At this time, if we return to the original, we will realize and understand the subtleties of the original language. The so-called "free translation" is the faithfulness to the original meaning but changing the original form . In the process of translation, the author should try to be as faithful as possible according to the meaning of the original text.

Example 4:

This is an effective form for the political and legal department to promote righteousness and deter criminals.It is expected that the detection of such a carefully planned case should be like seeking a needle in a haystack. Nowadays, it has come out in the wash, all the detainees are arrested and will be punished by the law. This is what the masses expected.

In this sentence, there are two four-character structures. In English, the set phases should be translated as "Heaven's vengeance is slow but sure, not as the net of Heaven has large meshes, but it lets nothing through.” The meaning of this sentence is: Justice, like a net, although not porous, will not let go of a bad man. Analogy of evil can not escape the punishment of law. Here we use the method of free translation, which is not as ambiguous as literal translation, but can make foreign readers more vividly understanding of the meaning of the sentence.

\subsection{Annotation}

Although some four-character structures can express their connotations by the method of literal translation, it still brings about comprehension barrier for target language readers. Because the images of some four-character structures can cause cultural conflict after adopting the method of literal translation and semantic error, in this condition, it is imperative to add up the annotation based on the method of literal translation, which can help target language readers have a good knowledge of content and intention of source text.

Example 5:

Where there is a will, there is a way; cutting off all means of retreat (1), such an extremely dangerous topography is ultimately owned by the State of Chu; God will not fail those who have firm will, just like Goujian revenge, he only used three thousand troops to eliminate Wu.

Note:(1) The ancient historical records Shi Chi states that in order to save the State of Zhao, 
General Xiang Yu's army personally took only three days of dry food per person, sank the boat crossing the river, breaking the cauldrons to encourage the soldiers under his command. In this way, he led the soldiers with the determination to win.

Example 6:

Obedient children use Shu Shui to satisfy their parents, although they are poor. Strict fathers teach their children to be an upright person.

Note: "Shu Shui " refers to beans and water. It also refers to the most ordinary foods; "satisfy" refers to wining favors, and specifically refers to serving parents. Use beans and water to care for your parents and win their parents' favor. It means although the people are in poverty they are filial for parents. "Strict fathers teach their children to be an upright person" means that fathers should educate their children about their rules of behavior. This is the father's intention to love his son. Shao Hao said that he inherited the cause of his father's generation and was able to prosper and to carry forward the cause of his ancestors. He did not insult the reputation of his parents.

\subsection{Omission}

The Chinese language prefers gorgeous words, emphasizes the rhythm of confrontation, neatness and balance; while English requires simple and natural terms. For English-speaking readers, they like clarity and effectiveness in their communications, and even be seen to some extent as an over-the-top verb and an exaggeration. There is also a phenomenon in which synonyms are repeated in Chinese words, which is very different from English. There is also a repetitive structure in the four-character grid structure. A large number of four-character grids in Chinese are repetitive structures of meaning, that is, the meaning of the first two words and the last two words in the four-character structure is the same or similar. In the process of translation, the original text should be analyzed at the information level, the similar words should be deleted, the main information of the sentences should be conveyed, the redundant information should be eliminated, and the "complexity" should be simplified to realize the functions of the original and translated information. The equivalence also makes the target readers understand and accept better. The following examples will discuss how to simplify the process.

Example 7:

I was in a state of panic and anxiety, and his irritation could not be borne by him, such causing trouble for the work of the public security department.

In this sentence, for the readers to understand the informative function of the translation correctly, the first thing to know is that the exact meanings of the two phases. The literal meaning refers to a twinge of panic and fear. It means being worried, describes one's concerns, sadness and worries. Comparing two expressions, they have similar meanings, all refering to mental tension, worry and fear. So there is no need to translate them word by word. We just use two words to express the state of mind: panic and anxiety. Nida believes that equivalence is much more than the transmission of information. The key is the expression of language. This is precisely reflected in the complexity of the semantic repetition of the four-character structures.

Example8:

I was sitting in a jeep and joined a mighty procession. This section of the asphalt road run across the county, and I did not know where they have got the news. People have already flocked to the road and dozens of miles of roads had been narrowed down by the walls of people.

The four-character phrase in this sentence refers to the tremendous flow of people. In order to avoid duplication, to achieve a simple effect, in the translation of this four-character phrase is cumbersome for the sake of simplicity, the direct translation of "mighty" can achieve simple and clear results. 


\section{Conclusions}

Generally speaking, in the practice of translation, according to the characteristics of different types of four-character structures, the appropriate translation method should be selected. It is necessary to be faithful to the original text, and also to pay attention to the fluency of the translation, so as to leave a deep impression on the readers. The four-character structures has the characteristics of beauty in sense, sound and style. However, due to differences in language and culture, rich information or unique expression features are often not fully conveyed or reproduced in translation. The target language often fails to achieve its semantic and expressive effects. On the other side, Nida's functional equivalence theory provides theoretical guidance for the translation of the four-character structures, enabling the translator to translation the four-character phrases into English successfully.

Through this translation practice, the translator deeply feels that the Chinese-English translation of legal novels on documentary subject matter not only requires the translator to have extensive knowledge of the relevant professional knowledge, but also requires the translator to have a solid English foundation and be familiar with the sentence patterns and language styles of the documentary literature.

\section{References}

[1] Femando C. idioms and idiomaticity.[M] Shanghai: Shanghai Foreign Language Education Press, 1997.

[2] Gentzler E. Contemporary Translation Theories.[M] London: Routledge, 1993.

[3] Lefevere, A. Translation/ History/Culture(ED).[M] Shanghai: Shanghai Foreign Language Education Press, 2004. 